\title{
HIGHER SUSTAINABILITY OF MENTAL MODELS ACQUIRED FROM A DIGITAL GAME IN COMPARISON WITH A LIVE ACTION ROLE- -PLAYING GAME AND A TRADITIONAL LECTURE
}

by

MICHAELA SLUSSAREFF** ${ }^{*}$ IIT ŠISLER ${ }^{* * *}$

This article analyses the effectivity of teaching EU law using various educational media. It specifically explores the differences between, and sustainability of, mental models constructed within three various educational environments: (1) a digital game played on PCs, (2) a non-digital role-playing game, and (3) a traditional lecture with discussions. We conducted a laboratory experiment, in which participants (253 high school students, $M=112, F=141$, mean age 16.5) studied EU laws, institutions, and politics in the three above-mentioned environments. We evaluated and compared mental models participants constructed through content analysis of the concept maps they drew immediately after the experiment and others made one month later. Within the analysis, we studied content, architecture, and changes in mental models over time. The resulting data offer unique insight into the process of mental models creation and sustainability thereof within game-based learning; particularly, when using a digital game. Digital game-based learners' concept maps differed in comparison with those of the educational role-playing and traditional lecture groups; the students tended to keep less altered mental models

During writing this article, the authors were supported by the Charles University project Progress Q15. Vit Šisler was further supported by the European Regional Development Fund-Project "Creativity and Adaptability as Conditions of the Success of Europe in an Interrelated World" (No. CZ.02.1.01/0.0/0.0/16_019/0000734) and Charles University project PRIMUS/HUM/03. We would like to thank Cyril Brom for comments on the early version of this text.

* michaela.slussareff@ff.cuni.cz, Assistant Professor, Institute of Information Science and Librarianship, Faculty of Arts, Charles University, Czech Republic.

*** vit.sisler@ff.cuni.cz, Assistant Professor, Institute of Information Science and Librarianship, Faculty of Arts, Charles University, Czech Republic . 
in their long-term memory: even after the one month period. The results suggest that a digital game-based learning environment could be more successful in mental model retention and for efficacy of future recall; particularly, when dealing with complex phenomena like EU law.

\section{KEY WORDS}

Concept Maps, Digital Game-based Learning, Mental Models

\section{INTRODUCTION}

Teaching EU law, the role of European institutions and EU politics in a formal school system is a challenging task; particularly, at the high school level. These issues are complex and cannot be easily explained through the frontal lectures that still dominate higher education in the Czech Republic. ${ }^{1}$ As Baroncelli, Farneti and Vanhoonacker argue, teaching EU law should
"move beyond traditional knowledge-based learning" and utilize
a "learning to learn paradigm with emphasis on more pragmatic problem-
-solving and problem-based learning."

The rise of constructivist theories of learning has triggered a variety of new methods and learning environments for teaching EU law: including project-based learning and educational simulations. ${ }^{3}$ More recently, this domain has also begun to benefit from using computer-based instruction and digital games. $^{4}$

Based on some studies, digital games in particular are able to simulate tasks involving the same cognitive processes required for task performance in the real world. ${ }^{5}$ They can also provide immediate feedback that might induce correction of misunderstood information or mental model re-

1 Švaříček, R., Šed’ová, K. and Šalamounová, Z. (2012) Komunikace ve školní trúdě. Praha: Portál, pp. 161-170.

2 Baroncelli, S., Farneti, R. and Vanhoonacker, S. (2014) Introduction - Teaching European Studies: Educational Challenges. In: Stefania Baroncelli, Roberto Farneti, Ioan Horga and Sophie Vanhoonacker (eds.). Teaching and Learning the European Union: Traditional and Innovative Methods. Dordrecht: Springer, p. 2.

3 Jones, R. and Bursens, P. (2014) Assessing EU Simulations: Evidence from the Trans-Atlantic EuroSim. In: Stefania Baroncelli, Roberto Farneti, Ioan Horga and Sophie Vanhoonacker (eds.). Teaching and Learning the European Union: Traditional and Innovative Methods. Dordrecht: Springer.

4 Ibid; Brom, C. et al. (2016) You like it, you learn it: affectivity and learning in competitive social role play gaming. International Journal of Computer-Supported Collaborative Learning, 11. 
-construction. ${ }^{6}$ Despite many studies supporting the educational value and efficiency of a digital game-based approach to learning ${ }^{7}$, other reports ${ }^{8}$ argue that there is no significant proof that digital games affect learning positively; i.e. as compared to traditional instruction or multimedia presentations. Nevertheless, most authors concur with regards to positive emotional and motivational responses in students interacting with games incorporated into educational programs. ${ }^{9}$

The process of information delivery within game-based educational treatment and frontal teaching differs on many levels: game elements as simulation, immediate feedback and emotional engagement seem to be essential ingredients of learning.

The aim of this study is to explore the process of mental models' construction within three different educational environments: (1) a digital game played on PCs, (2) a non-digital role-playing game, and (3) a traditional lecture with discussions. We conducted a laboratory experiment, in which a sample of 253 high-school students $(M=112, F=141$, mean age 16.5) studied EU laws, European institutions, and EU politics in the three above-mentioned environments. We subsequently evaluated

5 Tobias, S. and Fletcher, D. (2011) Learning from Computer Games: A Research Review. In: Stefan De Wannemacker, Sylke Vandercruysse and Geraldine Clarebout (eds.). Serious Games: The Challenge. Communications in Computer and Information Science. Springer, Berlin, Heidelberg.

6 Moreno, R. and Mayer, R. (2007) Interactive multimodal learning environments: Special issue on interactive learning environments: Contemporary issues and trends. Educational Psychology Review.

7 Schneider, S. et al. (2018) Anthropomorphism in decorative pictures: benefit or harm for learning? Journal of Educational Psychology, 110 (2); Plass, J. and Kaplan, U. (2016) Emotional Design in Digital Media for Learning. In: Sharon Tettegah and Martin Gartmeier (eds.). Emotions, Technology, Design, and Learning; Sitzmann, T. (2011) A Meta-Analytic Examination of the Instructional Effectiveness of Computer-Based Simulation Games. Personnel Psychology, 64 (2).

8 Münchow, H., Mengelkamp, C. and Bannert, M. (2017) The better you feel the better you learn: Do warm colours and rounded shapes enhance learning outcome in multimedia learning? Education Research International; Clark, D. B., Tanner-Smith, E. E. and Killingsworth, S. S. (2016) Digital Games, Design, and Learning: A Systematic Review and Meta-Analysis. Review of Educational Research, 86 (1); Wouters, P. et al. (2013) A Meta-Analysis of the Cognitive and Motivational Effects of Serious Games. Journal of Educational Psychology, Advance online publication; Adams, D. M. et al. (2012) Narrative games for learning: Testing the discovery and narrative hypotheses. Journal of Educational Psychology, 104 (1).

9 Ryan, R. M. and Deci, E. L. (2000) Intrinsic and Extrinsic Motivations: Classic Definitions and New Directions. Contemporary Educational Psychology, 25, p. 56; Brom, C., Šisler, V. and Slavík, R. (2010) Implementing digital game-based learning in schools: augmented learning environment of 'Europe 2045'. Multimedia Systems, 16 (1); Habgood, J. M. P. and Ainsworth, S. E. (2011) Motivating children to learn effectively: Exploring the value of intrinsic integration in educational games. Journal of the Learning Sciences, 20. 
and compared mental models for EU laws and politics that students constructed in the different environments.

We built our study on the theory of mental models mostly popularized by Johnson-Laird, for whom the mental model:

"has the same structure as the situation that it represents. Like an architect's model, or a molecular biologist's model, the parts of the model and their structural relations correspond to those of what it represents. [...] a mental model is also partial because it represents only certain aspects of the situation. ${ }^{10 "}$

Current research defines mental models as intrinsic representations of objects, ideas, or processes which individuals generate during cognitive functioning. The models contain presuppositions about the systems and causal rules and relations between their subsystems. People use these models to reason, describe, explain, predict phenomena, and/or generate expressed models in various formats (e.g. verbal description, diagrams, simulations, or concrete models) to communicate their ideas to others or to solve problems. ${ }^{11}$

Through the analysis of mental models we aimed to provide complex insight into the architecture of learning outcomes within game-based learning. The research question was designed as a casual/effect question seeking "if and how game-based learning affects the construction and retention of mental models?" We hypothesized that the game-based educational approach (groups 1 and 2 mentioned above) will have a positive effect on the creation and retention of mental models. Specifically, we expected mental models students created within a game-based learning session to be more extensive and persistent over a longer period of time. The second hypothesis was directed at the digital game-based intervention and postulated that audiovisual elements in digital game-based learning will play a supportive role in the retention of mental models over longer periods of time. Thus, we expected the digital game-based group (group 1 mentioned above) to have more sustainable mental models.

10 Johnson-Laird, P. (2005) The history of mental models. In: The Cambridge Handbook of Thinking and Reasoning, p. 181.

11 Buckley, B. C. and Boulter, C. J. (2000) Investigating the role of representations and expressed models in building mental models. In: John Gilbert and Carolyn Boulter (eds.). Developing models in science education. Netherlands: Kluwer Academic Publishers, pp. $120-123$. 
The study was conducted as part of a larger research project examining the connection between positive affects triggered by a game and its related learning outcomes. ${ }^{12}$ This larger research was based on the experimental design outlined above, but it used extended methods for measuring knowledge gains through pen and paper knowledge tests, as well other methods of knowledge evaluation based on quantitative assessment. The outcomes clearly showed that both game-based approaches led to comparatively higher and - in the one-month observation period - more sustainable knowledge gains. The present study offers new, previously unpublished data based on qualitative approach while studying participating students' mental models.

We evaluated the mental models using content analysis of concept maps drawn by the participating students: both immediately after the educational intervention and one month later. Through a comparison of those two concept maps we were able to explore structural changes over time. The data indicates that we can follow structural differences in mental models acquired within a digital game-based educational session compared to a non-digital role-playing game and also a traditional lecture with discussions. Students using the digital game showed a remarkably wider tendency to keep their acquired mental model over time. More precisely, when students were asked to create a concept map one month later, those from the digital game group created a map that was $60 \%$ similar to the concept map created right after the workshop (4.4 repeated concepts from 7.2). On the contrary, students taking part in the traditional lecture or the non-digital role-play session tended to rebuild their concept map to a large degree: in their delayed, post-test concept maps they kept less than $50 \%$ of their previous map and more than half of the concepts they added were new (three repeated concepts out of 6.2 in the non-digital role-playing group and 2.9 repeated concepts out of 5.9 in the traditional lecture group).

This article presents not only the results of, but also introduces a possible use for simplified content analysis as a method for evaluating mental model acquisition within different educational environments. As far as we know, content analysis applied within concept map drawing is a method that is not currently applied in research on digital game-based learning.

12 Brom, C. et al. (2016) You like it, you learn it: affectivity and learning in competitive social role play gaming. International Journal of Computer-Supported Collaborative Learning, 11. 
Importantly in this regard, our study shows its promising possibilities in this field.

\section{THEORETICAL BACKGROUND}

\subsection{KNOWLEDGE ACQUISITION WITHIN THE CONSTRUCTIVIST APPROACH}

In order to understand the world, all humans construct internal representations or mental models that they constantly revise based on new knowledge, ideas, concepts and experiences. ${ }^{13}$ Nersessian claims that humans - thanks to their linguistic abilities - are able to create these models from a mere description, e.g. an oral description within a traditional lecture or from a lecture book..$^{14}$ Constructivists, on the other hand, suggest that theoretical instruction might not be sufficient in this process. ${ }^{15}$ They propose experience - or problem-based methods of learning, since the latter provide multiple dimensions of knowledge representation and thus foster multiple interconnections across knowledge components. Additionally, presentation of contradictory understandings and interpretations may help in this process ${ }^{16}$; thus, case studies, debates, individual and group summarizing, and team teaching are appropriate instructional activities for creating efficient mental models. Digital game-based learning processes are very close (similar) to the constructivist point of view. ${ }^{17}$

Mental Models: Overview. The most influential account of the concept of mental models is that of Johnson-Laird, who refers to a mental model specifically as a model having the same structure as the situation it represents. In his point of view, mental models are partial because they represent only certain aspects of a situation. ${ }^{18}$ Other authors define mental models as intrinsic representations of objects, ideas, or processes, which

13 Greca, I. M. and Moreira, M. A. (2000) Mental models, conceptual models, and modelling. International Journal of Science Education, 22.

14 Nersessian, N. J. (2002) The cognitive basis of model-based reasoning in science. In: Peter Carruthers, Stephen Stich and Michael Siegal (eds.). The Cognitive Basis of Science. Cambridge, UK: Cambridge University Press.

15 Novak, J. D. and Gowin, B. D. (1984) Learning how to learn. Cambridge, UK: Cambridge University Press, p. 161.

16 Kanuka, H. and Anderson, T. (1999) Using Constructivism in Technology-Mediated Learning: Constructing Order out of the Chaos in the Literature. Radical Pedagogy, p. 6.

17 Li, M. and Tsai, C. (2013) Game-Based Learning in Science Education: A Review of Relevant Research. Journal of Science Education \& Technology, 22 (6); Rosario, R. M. and Widmeyer, G. R. (2009) An Exploratory Review of Design Principles in Constructivist Gaming Learning Environments. Journal of Information Systems Education, 20 (3).

18 Johnson-Laird, P. (2005) The history of mental models. In: The Cambridge Handbook of Thinking and Reasoning, p. 203. 
individuals generate during cognitive functioning. ${ }^{19}$ The models contain presuppositions about a system and causal rules and relations between its subsystems. People use these models to reason, describe, predict phenomena, and/or generate expressed models in various formats (e.g. verbal description, diagrams, simulations, or concrete models) to communicate their ideas to others; or to solve problems. ${ }^{20}$ Mental models are stored in people's long-term memory ${ }^{21}$ and are retrieved and mobilized immediately to deal with encountered problems ${ }^{22}$. While doing so, people can construct completely new models in order to accommodate a novel situation. ${ }^{23}$ The process of mental simulation means that the models can be manipulated mentally or "run in the mind's eye" to make predictions about outcomes of causal states in the world. ${ }^{24}$

Mental Models: Assessment. To evaluate mental models, Mayer proposes written questioning focusing on (near or far) knowledge transfer and mental models' "runnability". ${ }^{25}$ Another technique in the assessment of learning processes and mental models themselves is concept mapping. ${ }^{26}$ Concept mapping is a tool used to visualize the organization and relationships between various concepts, thoughts and/or theories; it was developed by Novak in $1972^{27}$ and later described by Stewart et al. ${ }^{28}$ Although concept maps are well accepted as a viable assessment tool in qualitative

19 Buckley, B. C. and Boulter, C. J. (2000) Investigating the role of representations and expressed models in building mental models. In: John Gilbert and Carolyn Boulter (eds.). Developing models in science education. Netherlands: Kluwer Academic Publishers, p. 120.

20 Buckley, B. C. and Boulter, C. J. (2000) Investigating the role of representations and expressed models in building mental models. In: John Gilbert and Carolyn Boulter (eds.). Developing models in science education. Netherlands: Kluwer Academic Publishers; Greca, I. M. and Moreira, M. A. (2000) Mental models, conceptual models, and modelling. International Journal of Science Education, 22.

${ }^{21}$ Coll, R. K. and Treagust, D. F. (2003) Learners' mental models of metallic bonding: A cross-age study. Science Education, 87.

22 Vosniadou, S. and Brewer, W. (1992) Mental models of the Earth: A study of conceptual change in childhood. Cognitive Psychology, 24, p. 543.

23 Johnson-Laird, P. (1983) Mental models. Cambridge: MA: MIT Press, pp. 444-448.

24 Vosniadou, S. and Brewer, W. (1992) Mental models of the Earth: A study of conceptual change in childhood. Cognitive Psychology, 24, p. 537

25 Mayer, R. E. Dyck, J. and Cook, L. K. (1984) Techniques that help readers build mental models from scientific text: Definitions pretraining and signaling. Journal of Educational Psychology, 78 (6), p. 1091.

26 Besterfield-Sacre, M. et al. (2004) Scoring concept maps: An integrated rubric for assessing. Journal of Engineering Education, 93 (2).

27 Novak, J. D. and Cañas, A. J. (2008) The theory underlying concept maps and how to construct and use them. Pensacola: Florida Institute for Human and Machine Cognition.

28 Stewart, J., Van Kirk, J. and Rowell, R. (1979) Concept maps: A tool for use in biology teaching. American Biology Teacher, 41 (3). 
educational research, there is no general agreement on a scoring technique. ${ }^{29}$ A number of researchers have attempted to develop accurate methods for assessing concept maps. The most traditional one was developed by Mintzes etal., who evaluated concept maps through the inner connections between their sub-concepts, i.e. they evaluated the validity of the connections and determined the latter's super/subordinate nature. ${ }^{30}$ Another approach was proposed by Bayram, who focused more on the whole structure of a map. ${ }^{31}$ He proposed a point system based on the map's hierarchical levels, correct propositions, and branches. One point was given for each hierarchical level; each relationship between concepts established by a correct connection. Ruiz-Primo et al. combined Novak's and Bayram's approaches and related each map to a criterion map created by an expert. ${ }^{32}$ The evaluation afterwards consists of measuring the degree of similarity to the expert map (expert map comparison). This method is mostly used in pedagogical research and the evaluation of educational goals.

Theories of Mental Models and Digital Games. A number of experiments have investigated the mental processes of literature readers and confirmed the hypothesis that readers spontaneously construct mental models to represent and reason about situations depicted in the text. ${ }^{33}$ Readers mostly imagined situations by "being in the place of an observer". ${ }^{34}$ There remain questions about what kind of experience can be created by a game (digital or non-digital) and what differences it brings to mental modelling processes and their outcomes. Digital games, considered a medium for the representation of information, offer novel ways to represent complex models and themes; they create new environments for perceiving new kinds of information and experiences. Similar to mental models, game

29 Yun Soo, L., Yongkyu, J. and Minsoo, K. (2015) Validity and Responsiveness of Concept Map Assessment Scores in Physical Education. Physical Educator, 72 (2); Besterfield-Sacre, M. et al. (2004) Scoring concept maps: An integrated rubric for assessing. Journal of Engineering Education, 93 (2).

30 Mintzes, J. J., Wandersee, J. H. and Novak, J. D. (2001) Assessing understanding in biology. Journal of Biological Education, 35 (3).

31 Bayram, S. (1995) The effectiveness of concept and software mapping for representing student data and process schema in science. Thesis. University of Pittsburgh.

32 Ruiz-Primo, M. A. et al. (2001) On the validity of cognitive interpretations of scores from alternative concept-mapping techniques. Educational Assessment, 7 (2), p. 11.

33 Johnson-Laird, P. (1983) Mental models. Cambridge: MA: MIT Press, pp. 396-479; Zwann, R. A and Radvansky, G. A. (1998) Situation models in language comprehension and memory. Psychological Bulletin, 123, pp. 396-400.

34 Nersessian, N. J. (2008) Mental modeling in conceptual change. In: Stella Vosniadou (ed.). International handbook of research in conceptual change. New York: Routledge, p. 24. 
mechanics define all possible functions and relationships in a system. They also influence a game's playability. In this regard, Boyan postulates that to master the in-game challenges, a player must create a mental model of the intrinsic obstacles in the game world: a model that is similar or identical to the true computer game model.$^{35}$ Well-designed educational games constantly test players' prior mental models and embody the process of cognitive disequilibrium and resolution; they foil expectations (create cognitive disequilibrium) without exceeding the player's capacity to succeed. Interacting with a game typically requires a constant cycle of hypothesis formulation, testing, and revision. ${ }^{36}$ Traditional lectures influence the creation and conceptual change of mental models through theoretical description, explanation, questioning, and discussion. Games, on the contrary, immerse their users directly in the topic and let them create, recreate and test mental models through (inter)action.

Similarly, the theory of multimedia learning proposes that multimedia platforms play an important role in knowledge acquisition and mental modelling. ${ }^{37}$ The the process of transferring knowledge to long-term memory and its further reconstruction are still not clear. However, new memory models and the theory of multimedia learning provide a so-called embedded processes model. This model argues that working memory is not a separate cognitive system but is the activated part of long-term memory. ${ }^{38}$ Activation is therefore supported by focusing one's attention (voluntary and involuntary) which, particularly in multimedia learning, is strengthened by using positive, or strongly connected, images. ${ }^{39}$ Our study's research question and hypotheses are built on this theoretical background.

35 Boyan, A. and Sherry, J. L. (2011) The Challenge in Creating Games for Education: Aligning Mental Models with Game Models Child Development Perspectives. The Society for Research in Child Development, 5 (2), p. 5.

36 Van Eck, R. (2006) Digital Game-Based Learning: It's Not Just Digital Natives Who Are Restless. Educause Review, 41 (2).

37 Mayer, R. E. and Johnson, C. I. (2010) Adding instructional features that promote learning in a game-like environment. Educational computing research, 42 (3).

38 Schweppe, J. and Rummer, R. (2014) Attention, Working Memory, and Long-Term Memory in Multimedia Learning: An Integrated Perspective Based on Process Models of Working Memory. Educational Psychology Review, 26.

39 Schneider, S. et al. (2018) Anthropomorphism in decorative pictures: benefit or harm for learning? Journal of Educational Psychology, 110 (2); Plass, J. and Kaplan, U. (2016) Emotional Design in Digital Media for Learning. In: Sharon Tettegah and Martin Gartmeier (eds.). Emotions, Technology, Design, and Learning. 


\subsection{PRESENT STUDY}

Building on the current findings mentioned earlier ${ }^{40}$ and the theory of mental models mainly popularized by Johnson-Laird ${ }^{41}$, we decided to test their theoretical postulates. Our research question asks if and how does game-based learning affect the construction and retention of mental models.

We were mostly interested in real schooling possibilities, so we closely copied a typical, formal schooling environment and used teaching approaches accessible to today's teachers. We compared three different educational environments while adopting a controlled experiment design with one experimental and two control groups: (1) a digital game (the experimental group) containing strong connected visuals and an interactive simulation model; (2) a non-digital role-playing game copying the digital game but without PCs and lacking the multimedia visual element; and (3) a traditional lecture with discussions.

We hypothesized (our first hypothesis) that the game-based educational approach (groups 1 and 2 mentioned above) will have a positive effect on the creation and retention of students' mental models. Specifically, we expected the mental models that students created within a game-based learning session to be more extensive and persistent over a longer period of time. In other words, after one month, both game-based groups will lose a smaller part of their mental model. Afterwards, we expected (our second hypothesis) that the audiovisual elements so typical for digital game-based learning will play a supportive role in the retention of mental models. Thus, we anticipated that the digital game-based group (group 1 mentioned above) would have more sustainable mental models, i.e. after one month a significantly larger part of their mental model would remain unchanged.

This study used a mix of qualitative and quantitative approaches. Therefore, we present their development and our use of a simplified content analysis applied to the interpretation of concept maps. This approach can be considered a method for evaluating mental model acquisition within different educational environments. In the discussion we describe its limitations and potential for future research.

\footnotetext{
40 Ibid.

41 Johnson-Laird, P. (2005) The history of mental models. In: The Cambridge Handbook of Thinking and Reasoning, pp. 185-187.
} 


\section{METHODS}

\subsection{RESEARCH INSTRUMENT: EUROPE 2045}

We used a modified version of the educational simulation Europe $2045^{42}$ as a research instrument. The game has three educational goals: (1) to improve students' high-level skills, i.e. to increase their ability to discuss, negotiate, work in teams, and make group decisions; (2) to familiarize students with facts (such as the geographies of European countries, EU institutions and policies, typologies of political inclinations); and (3) help students acquire mental models of large-scale processes and socio-political notions (such as a model of "energy dependence" or "liberalism").

Europe 2045 was released in 2008 and was successfully integrated into the formal schooling system. ${ }^{43} \mathrm{Up}$ to now, the game has been used in dozens of Czech high schools and played by more than 4,000 students. Europe 2045 was modified for the purposes of this experimental research.

The modified game was limited to eight players and combined the principles of multi-player online videogames and social role-playing games. One part of the game is played in a multi-user virtual environment (on a PC) and the second part in a classroom where role-playing game activities take place. A teacher is always present and takes on the role of discussion moderator.

In the beginning, each user chooses a project in the game to play out (e.g. Social Europe - Social Democracy, Liberal Europe - Liberalism, etc.). The project is a vision of how the EU should look in the future. Therefore, players need to achieve structural changes to bring the EU closer to their project goal. The project is always related to one EU member state that students are chosen to represent; they define that country's domestic policy. Students also take on the role of an EU representative and have an opportunity to present drafts for policy changes to EU governing bodies. Discussions about these changes take place in the classroom and can be conceived as a simulation of official EU negotiations within institutions: such as the European Parliament, the Council of Europe, and the Foreign Affairs Council. The winners of the game are the students who pushed through

42 Šisler, V. and Brom, C. (2008) Designing an Educational Game: Case Study of 'Europe 2045'. Transactions of Edutainment I, 5080.

43 Brom, C., Šisler, V. and Slavík, R. (2010) Implementing digital game-based learning in schools: augmented learning environment of 'Europe 2045'. Multimedia Systems, 16 (1). 
or refused as many policy changes as possible in order to re-create the EU according to their project's vision. Players can also support votes for their policies by creating informal pacts with other state leaders. The game features both collaborative and competitive aspects at the same time. Throughout the game, students face global situations represented by the game scenario. The game was played during a one-day workshop and game-play lasted about four hours.

\subsection{RESEARCH DESIGN}

The present study was part of a larger experiment examining the connection between positive affects triggered by a game and learning outcomes therefrom. ${ }^{44}$ This study was based on set of pen and paper knowledge tests that were distributed at the same time as the task for drawing mentioned concept maps.

The timetable and all workshop activities were strictly defined, so we could assure comparability of research variables in all the groups. The same amount of time was dedicated to learning activities, frontal teaching sessions, pauses, similar vocabulary and communication styles, etc. To avoid environmental issues that might threaten the study's reliability, we chose a laboratory design - the experiment did not take place at students' ordinary schools but rather in classrooms at Charles University and teachers were hired specifically for the experiment. To minimize possible bias caused by specific teacher personalities, we worked with a group of eight teachers: all males younger than 35 years of age, with a similar clothing style, short hair, and similar speech and teaching styles. These teachers rotated through different classrooms and taught in all three types of research groups. Within the experiment, we organized 14 workshop days (six hours); always for one high school class (15-16 participants).

Distribution of students into subgroups was not random. In order to have a comparable sample, participants were asked to fill out a pre-questionnaire assessing their knowledge of EU affairs after a short introduction to the project. Students with similar results were grouped and then assigned randomly to the experimental conditions. Thus, each subgroup had the same proportion of students with each level

44 Brom, C. et al. (2016) You like it, you learn it: affectivity and learning in competitive social role play gaming. International Journal of Computer-Supported Collaborative Learning, 11. 
of knowledge. Gender was also taken into account; each group had similar gender representation. Students participated in only one selected treatment: digital game, non-digital game, or traditional lecture with discussions.

Digital game-based treatment. Students played the modified PC version of the game Europe 2045. The rounds of the game always had a similar design: four players selected by a computer were to propose a draft for a policy change; they had eight minutes to study the materials related to the game (mainly the online encyclopedia). The rest of the students could control their state or read materials about policies associated with their own projects or about policies proposed by the other four players. Afterwards, they were invited to turn away from the computer screens, and each student assigned to propose a policy change had exactly 1.5 minutes to introduce the policy and present its benefits. After that, there was an open discussion moderated by the teacher (2-3 minutes). When all four proposals were presented, there were five minutes of overall negotiations where the teacher challenged students to leave their seats and discuss ideas with other players individually. In the end, students voted separately on their own computers. The teacher presented the results at the beginning of the next round along with the players' current rankings in the game. The students played six rounds; always with eight students taking part.

Non-digital role-playing game. Students played the game Europe 2045 as a social role-playing game without PCs. This set-up copied the activities of the experimental game group but computer use was avoided. The voting system was simulated directly in the classroom using a voting urn. The in-game textual materials (encyclopedia texts) were printed out and distributed to the players. The schedule and the content were exactly the same as in the experimental game group except that players did not have the opportunity to control their state. Six to eight students took part.

Traditional lecture with discussions. Students did not play any game, but in the workshop the same content as used in the two previous groups was shared with students through non-game-based learning techniques: a traditional lecture and discussions about EU policies and projects. Since these students did not vote on policy drafts and did not interact with a European state model, the whole workshop for the traditional lecture control group was shorter. The game's introductory simulated scenario was replaced by an unrelated 40-minute-long frontal lecture on the EU and by a 20-minute-long, pen-and-paper mini-rebus about EU law. The content 
of those additional activities was not related to the experimental research topic and was not tested via concept maps. Six to ten students took part.

\subsection{RESEARCH APPARATUS}

Students' mental models were examined through concept maps that students drew right after the learning sessions (maps \#1) and one month later (maps \#2). There was one more map created before the educational workshop (maps \#0), but those were not analyzed. They served only as a training tool to assure the same level of understanding and experience with concept maps among all students.

For the evaluation, only participants who attended the educational workshop and the one month delayed testing sessions (so we could compare both maps \#1 and \#2) were chosen. Concept maps from 253 subjects were evaluated; 84 from the experimental digital game group, 99 from the control traditional lecture group and 70 from the control non-digital role-playing game group.

As mentioned above, at the very beginning of the educational workshop, students were asked to read a three- to four-sentence summary of eight political projects (each was a specific political project, e.g. liberal, conservative, environmental, multicultural, etc.) and choose three projects that interested them. After that, they were assigned one project. For their concept map, students got an empty sheet with an ellipse in the middle and the following instructions: "Write in the empty ellipse the name of the political philosophy you were reading about today. In the surrounding area write the key concepts related to this philosophy." Before map creation, the teacher presented the following instructions: "For my mental map, I chose anarchism. Actually, I just recently saw a documentary on anarchism, so I know a lot about it... What am I thinking of now?" ... writes "Anarchism"' into the ellipse. "On which side of the political spectrum?" ... writes "radical left" and connects it directly to "Anarchism". "As it is on the left side of the political spectrum, it tries to enforce..." ... writes "social justice" and connects it directly to "radical left". "Everyone has probably heard of..." ... writes "Sex Pistols" and connects it directly to "Anarchism". "I think its origin is..." ... writes "France" and connects it directly to "Anarchism", etc. 


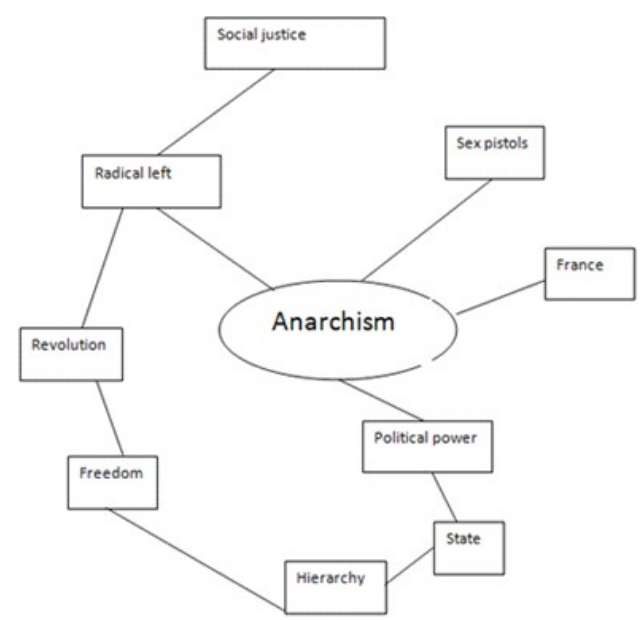

Diagram 1: Concept map drawn by teacher as an instructional example

Within the evaluation, we applied the traditional quantitative measures of content analysis: keyword frequencies and spatial measurements for maps (branching, subcategorizing). ${ }^{45}$ Two evaluators independently analyzed each entry word in map \#1 and followed its development in map \#2. The base value for the content analysis was a "sub-concept", a fragment of a concept map related to one specific theme (so it could contain more than one entry). For example, in the exemplary concept map described above (see Diagram 1) eight entries would have been counted: (1) political power + state; (2) hierarchy; (3) France; (4) Sex Pistols; (5) freedom; (6) revolution; (7) radical left; and (8) social justice.

Content analysis of maps \#1. We utilized two categories for evaluating sub-concepts in maps \#1: (1) relevant, (2) irrelevant (unrelated to the theme). Thus, the first step in the content analysis consisted merely of evaluating and quantifying the incorporated sub-concepts.

Content analysis of maps \#2. In the evaluation of maps \#2, we made comparisons with maps \#1 (those made by similar students). Therefore, we used six categories for the sub-concepts: (1) forgotten (present in map \#1 but not in map \#2); (2) remained unchanged; (3) changed to "upgraded" form (the sub-concept in map \#2 was in a more apposite position or more appropriate and/or developed phrase than in map \#1); (4) changed to a "downgraded" form (a less apposite position or less appropriate and/or

${ }^{45}$ Neuendorf, K. (2002) The Content Analysis Guidebook. Thousand Oaks, CA: Sage Publications, pp. 212-214. 
developed phrase than in map \#1); (5) new (present in maps \#2 but not present in maps \#1); (6) irrelevant.

We considered entries or groups of entries that developed or concretized the entries from map \#1 to be upgraded sub-concepts in maps \#2. For example "P.-J. Proudhon" drawn as an additional branch to "France" would be considered an upgraded sub-concept (see Diagram 1). The student had developed a hierarchy branching into the upper class. Additionally, "punk rock movement" written in map \#2 instead of "Sex Pistols" in map \#1 would be considered an upgraded sub-concept, because it puts forward a general concept that concretizes social forces that helped disseminate anarchist ideas in the 1970s.

The downgraded sub-concepts lacked a rich branching or were more reductive in comparison with their corresponding values in map \#1. For instance, were "social justice" missing in map \#2 that would be considered a downgraded sub-concept. "No-government" written instead of "political power" and/or "state" would be considered a downgraded sub-concept as well. In such cases, the student used a simplified concept that did not represent the issue's complexity.

Indeed, the comparison between individual maps \#1 and maps \#2 was crucial for the analysis. Additional qualitative analysis was also used to explain differences in greater detail, i.e. the character of the content was evaluated; trends in the maps' content were described.

\section{RESULTS}

Two raters evaluated each map independently. To ensure evaluation reliability, their outcomes were compared to each other using an internal consistency test, Cronbach's alpha ( $\alpha$ ). This test can show possible statistical variability in evaluations. All values were higher than 0.7 , thus statistically consistent. The average $\alpha$ for all results was $\alpha=0.931$. So for the final evaluation we used the mean values from both raters. To analyze the differences in the group means in the three conditions we used the one-way ANOVA test with a statistical significance $\mathrm{p}<.05$. When the ANOVA showed a significant difference, we applied a Tukey HSD range test to identify which means (group conditions) resulted from others and by how much. The rest of the data was commented in discussions. 


\begin{tabular}{cccc}
\hline Group & & Maps \#1 entries & Irrelevant entries \\
\hline \multirow{2}{*}{ Digital game } & M & 8.45 & 0.33 \\
& SD & 2.87 & 0.71 \\
Traditional lecture & M & 7.19 & 0.56 \\
Non-digital game & SD & 2.67 & 1.23 \\
& M & 7.46 & 0.65 \\
& SD & 2.56 & 1.19 \\
\hline
\end{tabular}

Table 1: Maps \#1 descriptive statistics

Further analysis of the maps \#1 (see Table 1) reveals the influence of the educational approach on the extensiveness of the concept maps and on the amount of relevant sub-concepts included. Maps \#1 created by students who played the digital game included more entries (the concept maps were bigger and more branched) than those created by students who followed the role-play based game or the traditional lecture with in-class discussions. There was a statistically significant effect, with small effect size from type of educational activity on the extensiveness of students' mental models at the $\mathrm{p}<.05$ level for the three conditions, $\mathrm{F}(2,250)=5.218, \mathrm{p}=.006$, $\eta 2=.040$. Post hoc comparisons using the Tukey HSD test indicated that the mean score for the amount of concept map entries in the digital game treatment $(\mathrm{M}=8.45, \mathrm{SD}=2.87)$ was significantly higher than for the non-digital role-playing game and traditional lecture treatments. The non-digital role-playing game mean score was $7.46(\mathrm{SD}=2.56)$ and the traditional lecture mean score was $7.20(\mathrm{SD}=2.67)$ for sub-concepts. The amount of irrelevant entries in the concept maps \#1 was comparable across all three groups $F(2,250)=1.837, p=0.161, \eta 2=.014$.

After one month, all students lost a roughly constant amount of knowledge (missing entries in concept maps \#2), thus the difference in the map size remained: the mean score for the digital game treatment was $7.21(\mathrm{SD}=2.79)$, for the non-digital role-playing game $6.18(\mathrm{SD}=2.35)$, and for the traditional lecture $5.90(\mathrm{SD}=2.92)$. 


\begin{tabular}{|c|c|c|c|c|c|c|c|}
\hline Group & & $\begin{array}{c}\text { Maps \#2 } \\
\text { entries }\end{array}$ & New & Repeated & $\begin{array}{c}\text { Repeated - } \\
\text { upgraded }\end{array}$ & $\begin{array}{l}\text { Repeated - } \\
\text { downgraded }\end{array}$ & Irrelevant \\
\hline \multirow{2}{*}{$\begin{array}{l}\text { Digital } \\
\text { Game }\end{array}$} & M & 7.21 & 2.79 & 4.42 & 0.45 & 0.07 & 0.17 \\
\hline & SD & 2.79 & 1.79 & 2.09 & 0.66 & 0.26 & 0.45 \\
\hline \multirow{2}{*}{$\begin{array}{c}\text { Traditional } \\
\text { lecture }\end{array}$} & $\mathrm{M}$ & 5.90 & 3.03 & 2.88 & 0.07 & 0.05 & 0.51 \\
\hline & SD & 2.92 & 2.11 & 1.96 & 0.29 & 0.24 & 0.90 \\
\hline \multirow{2}{*}{$\begin{array}{l}\text { Non-digital } \\
\text { game }\end{array}$} & M & 6.18 & 3.15 & 3.03 & 0.06 & 0.13 & 0.59 \\
\hline & SD & 2.35 & 1.77 & 1.91 & 0.29 & 0.36 & 0.99 \\
\hline
\end{tabular}

Table 2: Maps \#2 descriptive statistics

Content analysis of the maps \#2 (see Table 2) revealed a significantly higher amount of repeated concepts (concepts that stayed in unchanged form compared to maps \#1) with large effect size in the digital game group. There was a statistically significant effect (caused by the type of educational activity) on the number of repeated concepts in the maps referring to the stability of students' mental models; $\mathrm{F}(2,250)=15.565, \mathrm{p}=.00$, $\eta 2=111$. Post hoc comparisons using the Tukey HSD test indicated that the mean score for the digital game treatment $(\mathrm{M}=4.42, \mathrm{SD}=2.09)$ was significantly higher than for the non-digital role-playing game treatment $(\mathrm{M}=3.03, \mathrm{SD}=1.91)$ and the traditional lecture treatment $(\mathrm{M}=2.88$, $\mathrm{SD}=1.96)$.

The digital game group seemed to build on knowledge gained during the educational workshop and did not create a new concept map - let us say mental model - when asked to present their knowledge. In comparison, maps \#2 in the traditional lecture group and the non-digital role-playing group contained more new entries than those repeated from maps \#1.

There was always a low proportion of irrelevant, upgraded or downgraded sub-concepts. So we did not use advanced statistical measurements.

\section{DISCUSSION}

Content analysis of students' concept maps revealed structural differences in mental models for students learning with the digital game compared to students learning with the non-digital role-playing game and traditional schooling methods. Those interacting with the digital game were obviously willing to put more sub-concepts into their concept maps - they drew larger 
and more branched maps. Although all three groups lost approximately the same amount of knowledge during the one-month period prior to the delayed testing, the large size of maps from the digital game-based group lasted. This might be caused by better involvement in learning supported by higher affective engagement with the digital game-based learning platform; i.e. as some previous research proposes. ${ }^{46}$

On the other hand, a mere number of sub-concepts integrated into a map does not directly mean better quality of the maps; and thus of mental models. As we have mentioned above, this study was part of a larger experimental study using the same research design as described above (for more details see Section 3.3.). ${ }^{47}$ Unlike the present study, knowledge gains in the larger experimental study were assessed based on different, mostly quantitative measures. The outcomes of the larger experimental study showed that both game-based approaches led to comparatively higher and more sustainable knowledge gains: as observed in the one-month, post-experiment period. ${ }^{48}$

In the context of these outcomes, we can assume that the significantly higher extensiveness of the concept maps created by the digital game-based group was not a characteristic of knowledge quality but rather a reflection on media used. The quantity of concepts in the digital game-based group was boosted mostly by the fact that students also imported unimportant details about discussed policies and agendas: content that is an inherent part of the graphical user interface in the digital game. Players were repeatedly exposed to this content; thus, it seems that those details stayed imprinted in their memories.

When analyzing the concept maps one month later, we could observe a decline of retention over time. All groups copied a similar forgetting curve; all three groups lost approximately the same amount of concepts: the digital game group lost $14.65 \%$, the non-digital role-playing game group lost $17.23 \%$, and the traditional lecture group $17.97 \%$.

Otherwise, the key outcome was that students who learned with the digital game tended rather to use the model they gained through

46 Wouters, P. et al. (2013) A Meta-Analysis of the Cognitive and Motivational Effects of Serious Games. Journal of Educational Psychology. Advance online publication; Um, E. et al. (2012) Emotional Design in Multimedia Learning. Journal of Educational Psychology, 104 (2).

47 Brom, C. et al. (2016) You like it, you learn it: affectivity and learning in competitive social role play gaming. International Journal of Computer-Supported Collaborative Learning, 11.

48 Ibid. 
the workshop: their maps \#1 (after the educational workshop) and \#2 (one month later) contained a high amount of similar entries (61.22\%). By contrast, students from the other two groups produced second concept maps considerably different from their first ones. The non-digital role-playing game group used on average $50.98 \%$ new concepts $(49.02 \%$ similar ones) and the traditional lecture group $51.24 \%$ new concepts ( $48.76 \%$ similar ones). It seems that their mental models are not as stable and do not last over time. Rather, one month later, students created a new model "on demand" when asked to do so. With regard to that point, our content analysis does not predicate on the quality of the students' knowledge, but rather the structure thereof. The fact that students use similar keywords, concepts and connections indicates that their mental model is more integrated and stable within their long-term memory.

As discussed above, the comparison with the expert maps proposes that the digital as well as the non-digital role-playing game leads to comparable quality of mental models. But content analysis shows that the media used within the game-based learning approach influences the way users work with acquired knowledge over the long-term. Such an outcome supports theories where multimedia platforms play an important role in knowledge acquisition and mental modelling. ${ }^{49}$ It seems that digital games that include additional audiovisual cues help create a long-lasting mental model that is easily recalled even after one month. Such an outcome confirms theories of strengthened focus of attention when using in-game positive or strongly connected pictures. ${ }^{50}$

Within this framework, our research provides preliminary evidence suggesting possible significant impact of multimedia learning on the process of mental model construction. Additional multimedia material seems to help students integrate greater amounts of information and construct viable mental models in their long-term memory: ones that are easily accessible over time. Furthermore, content analysis of concept maps seems to be a helpful tool for developing an understanding of mental

49 Mayer, R. E. and Johnson, C. I. (2010) Adding instructional features that promote learning in a game-like environment. Educational computing research, 42 (3).

50 Schneider, S. et al. (2018) Anthropomorphism in decorative pictures: benefit or harm for learning? Journal of Educational Psychology, 110 (2); Plass, J. and Kaplan, U. (2016) Emotional Design in Digital Media for Learning. In: Sharon Tettegah and Martin Gartmeier (eds.). Emotions, Technology, Design, and Learning. 
model development. Current digital game-based research provides mixed results.

This study contributes to the research community mainly by providing new insight for mental modelling; especially, for persons interested in multimedia learning and cognitive theories of learning within digital game-based learning. The results are particularly viable for formal education on EU law, institutions and politics at the high school level.

\section{LIST OF REFERENCES}

[1] Adams, D. M. et al. (2012) Narrative games for learning: Testing the discovery and narrative hypotheses. Journal of Educational Psychology, 104 (1), pp. 235-249.

[2] Baroncelli, S., Farneti, R. and Vanhoonacker, S. (2014) Introduction - Teaching European Studies: Educational Challenges. In: Stefania Baroncelli, Roberto Farneti, Ioan Horga and Sophie Vanhoonacker (eds.). Teaching and Learning the European Union: Traditional and Innovative Methods. Dordrecht: Springer, pp. 157-185.

[3] Bayram, S. (1995) The effectiveness of concept and software mapping for representing student data and process schema in science. Thesis. University of Pittsburgh.

[4] Besterfield-Sacre, M. et al. (2004) Scoring concept maps: An integrated rubric for assessing. Journal of Engineering Education, 93 (2), pp. 105-115.

[5] Boyan, A. and Sherry, J. L. (2011) The Challenge in Creating Games for Education: Aligning Mental Models with Game Models Child Development Perspectives. The Society for Research in Child Development, 5 (2), pp. 82-87.

[6] Brom, C., Šisler, V. and Slavík, R. (2010) Implementing digital game-based learning in schools: augmented learning environment of 'Europe 2045'. Multimedia Systems, 16 (1), pp. 23-41.

[7] Brom, C. et al. (2016) You like it, you learn it: affectivity and learning in competitive social role play gaming. International Journal of Computer-Supported Collaborative Learning, 11, pp. 313-348.

[8] Buckley, B. C. and Boulter, C. J. (2000) Investigating the role of representations and expressed models in building mental models. In: John Gilbert and Carolyn Boulter (eds.). Developing models in science education. Netherlands: Kluwer Academic Publishers, pp. 119-135.

[9] Clark, D. B., Tanner-Smith, E. E. and Killingsworth, S. S. (2016) Digital Games, Design, and Learning: A Systematic Review and Meta-Analysis. Review of Educational Research, 86 (1), pp. 79-122. 
[10] Coll, R. K. and Treagust, D. F. (2003) Learners' mental models of metallic bonding: A cross-age study. Science Education, 87, pp. 685-707.

[11] Greca, I. M. and Moreira, M. A. (2000) Mental models, conceptual models, and modelling. International Journal of Science Education, 22, pp. 1-11.

[12] Habgood, J. M. P. and Ainsworth, S. E. (2011) Motivating children to learn effectively: Exploring the value of intrinsic integration in educational games. Journal of the Learning Sciences, 20, pp. 169-206.

[13] Johnson-Laird, P. (1983) Mental models. Cambridge: Cambridge University Press.

[14] Johnson-Laird, P. (2005) The history of mental models. In: The Cambridge Handbook of Thinking and Reasoning, pp. 179-212.

[15] Jones, R. and Bursens, P. (2014) Assessing EU Simulations: Evidence from the Trans-Atlantic EuroSim. In: Stefania Baroncelli, Roberto Farneti, Ioan Horga and Sophie Vanhoonacker (eds.). Teaching and Learning the European Union: Traditional and Innovative Methods. Dordrecht: Springer, pp. 157-185.

[16] Kanuka, H. and Anderson, T. (1999) Using Constructivism in Technology-Mediated Learning: Constructing Order out of the Chaos in the Literature. Radical Pedagogy.

[17] Li, M. and Tsai, C. (2013) Game-Based Learning in Science Education: A Review of Relevant Research. Journal of Science Education E Technology, 22 (6), pp. 877-898.

[18] Mayer, R. E., Dyck, J. and Cook, L. K. (1984) Techniques that help readers build mental models from scientific text: Definitions pretraining and signaling. Journal of Educational Psychology, 78 (6), pp. 1089-1106.

[19] Mayer, R. E. and Johnson, C. I. (2010) Adding instructional features that promote learning in a game-like environment. Educational computing research, 42 (3), pp. 241-265.

[20] Mintzes, J. J., Wandersee, J. H. and Novak, J. D. (2001) Assessing understanding in biology. Journal of Biological Education, 35 (3), pp. 118-124.

[21] Moreno, R. and Mayer, R. (2007) Interactive multimodal learning environments: Special issue on interactive learning environments: Contemporary issues and trends. Educational Psychology Review, pp. 309-326.

[22] Münchow, H., Mengelkamp, C. and Bannert, M. (2017) The better you feel the better you learn: Do warm colours and rounded shapes enhance learning outcome in multimedia learning? Education Research International.

[23] Nersessian, N. J. (2002) The cognitive basis of model-based reasoning in science. In: Peter Carruthers, Stephen Stich and Michael Siegal (eds.). The Cognitive Basis of Science. Cambridge, UK: Cambridge University Press, pp. 133-153. 
[24] Nersessian, N. J. (2008) Mental modeling in conceptual change. In: Stella Vosniadou (ed.). International handbook of research in conceptual change. New York: Routledge, pp. 391-416.

[25] Neuendorf, K. (2002) The Content Analysis Guidebook. Thousand Oaks, CA: Sage Publications.

[26] Novak, J. D. and Cañas, A. J. (2008) The theory underlying concept maps and how to construct and use them. Pensacola: Florida Institute for Human and Machine Cognition.

[27] Novak, J. D. and Gowin, B. D. (1984) Learning how to learn. Cambridge, UK: Cambridge University Press, pp. 133-143.

[28] Plass, J. and Kaplan, U. (2016) Emotional Design in Digital Media for Learning. In: Sharon Tettegah and Martin Gartmeier (eds.). Emotions, Technology, Design, and Learning, pp. 131-162.

[29] Rosario, R. M. and Widmeyer, G. R. (2009) An Exploratory Review of Design Principles in Constructivist Gaming Learning Environments. Journal of Information Systems Education, 20 (3), pp. 289-300.

[30] Ruiz-Primo, M. A. et al. (2001) On the validity of cognitive interpretations of scores from alternative concept-mapping techniques. Educational Assessment, 7 (2), pp. 99-141.

[31] Ryan, R. M. and Deci, E. L. (2000) Intrinsic and Extrinsic Motivations: Classic Definitions and New Directions. Contemporary Educational Psychology, 25, pp. 54-67.

[32] Schneider, S. et al. (2018) Anthropomorphism in decorative pictures: benefit or harm for learning? Journal of Educational Psychology, 110 (2), pp. 218-232.

[33] Schweppe, J. and Rummer, R. (2014) Attention, Working Memory, and Long-Term Memory in Multimedia Learning: An Integrated Perspective Based on Process Models of Working Memory. Educational Psychology Review, 26, pp. 285-306.

[34] Sitzmann, T. (2011) A Meta-Analytic Examination of the Instructional Effectiveness of Computer-Based Simulation Games. Personnel Psychology, 64 (2), pp. 489-528.

[35] Stewart, J., Van Kirk, J. and Rowell, R. (1979) Concept maps: A tool for use in biology teaching. American Biology Teacher, 41 (3), pp. 171-175.

[36] Šisler, V. and Brom, C. (2008) Designing an Educational Game: Case Study of 'Europe 2045'. Transactions of Edutainment I, 5080, pp. 1-16.

[37] Švaříček, R., Šed'ová, K. and Šalamounová, Z. (2012) Komunikace ve školní třídě. Praha: Portál. 
[38] Tobias, S. and Fletcher, D. (2011) Learning from Computer Games: A Research Review. In: Stefan De Wannemacker, Sylke Vandercruysse and Geraldine Clarebout (eds.). Serious Games: The Challenge. Communications in Computer and Information Science, Springer, Berlin, Heidelberg, pp. 6-17.

[39] Um, E. et al. (2012) Emotional Design in Multimedia Learning. Journal of Educational Psychology, 104 (2), pp. 485-498.

[40] Van Eck, R. (2006) Digital Game-Based Learning: It's Not Just Digital Natives Who Are Restless. Educause Review, 41 (2), pp. 16-30.

[41] Vosniadou, S. and Brewer, W. (1992) Mental models of the Earth: A study of conceptual change in childhood. Cognitive Psychology, 24, pp. 535-585.

[42] Wouters, P. et al. (2013) A Meta-Analysis of the Cognitive and Motivational Effects of Serious Games. Journal of Educational Psychology. Advance online publication, pp. 249-265.

[43] Yun Soo, L., Yongkyu, J. and Minsoo, K. (2015) Validity and Responsiveness of Concept Map Assessment Scores in Physical Education. Physical Educator, 72 (2), pp. 206-223.

[44] Zwann, R. A and Radvansky, G. A. (1998) Situation models in language comprehension and memory. Psychological Bulletin, 123, pp. 162-185. 